Article

\title{
Visible Light Responsive Strontium Carbonate Catalyst Derived from Solvothermal Synthesis
}

\author{
Pornnaphat Wichannananon ${ }^{1,2}$, Thawanrat Kobkeatthawin ${ }^{2}$ and Siwaporn Meejoo Smith ${ }^{2, *(1)}$ \\ 1 Center of Excellence for Innovation in Chemistry, Faculty of Science, Mahidol University, 272 Rama VI Rd., \\ Rajthevi, Bangkok 10400, Thailand; pornnaphat.w@gmail.com \\ 2 Center of Sustainable Energy and Green Materials and Department of Chemistry, Faculty of Science, \\ Mahidol University, 999 Phuttamonthon Sai 4 Road, Salaya, Nakorn Pathom 73170, Thailand; \\ kunthidakob@gmail.com \\ * Correspondence: siwaporn.smi@mahidol.edu; Tel.: +66-93593-9449
}

Received: 24 July 2020; Accepted: 11 September 2020; Published: 17 September 2020

\begin{abstract}
A single crystalline phase of strontium carbonate $\left(\mathrm{SrCO}_{3}\right)$ was successfully obtained from solvothermal treatments of hydrated strontium hydroxide in ethanol $(\mathrm{EtOH})$ at $100{ }^{\circ} \mathrm{C}$ for $2 \mathrm{~h}$, using specific Sr:EtOH mole ratios of 1:18 or 1:23. Other solvothermal treatment times (0.5, 1.0 and $3 \mathrm{~h}$ ), temperatures $\left(80\right.$ and $\left.150{ }^{\circ} \mathrm{C}\right)$ and different Sr:EtOH mole ratios (1:13 and 1:27) led to formation of mixed phases of Sr-containing products, $\mathrm{SrCO}_{3}$ and $\mathrm{Sr}(\mathrm{OH})_{2} \times \mathrm{H}_{2} \mathrm{O}$. The obtained products (denoted as 1:18 $\mathrm{SrCO}_{3}$ and 1:23 $\mathrm{SrCO}_{3}$ ), containing a single phase of $\mathrm{SrCO}_{3}$, were further characterized in comparison with commercial $\mathrm{SrCO}_{3}$, and each $\mathrm{SrCO}_{3}$ material was employed as a photocatalyst for the degradation of methylene blue (MB) in water under visible light irradiation. Only the 1:23 $\mathrm{SrCO}_{3}$ sample is visible light responsive $\left(\mathrm{E}_{\mathrm{g}}=2.62 \mathrm{eV}\right)$, possibly due to the presence of ethanol in the structure, as detected by thermogravimetric analysis. On the other hand, the band gap of 1:18 $\mathrm{SrCO}_{3}$ and commercial $\mathrm{SrCO}_{3}$ are 4.63 and $3.25 \mathrm{eV}$, respectively, and both samples are $\mathrm{UV}$ responsive. The highest decolourisation efficiency of $\mathrm{MB}$ solutions was achieved using the 1:23 $\mathrm{SrCO}_{3}$ catalyst, likely due to its narrow bandgap. The variation in colour removal results in the dark and under visible light irradiation, with radical scavenging tests, suggests that the high decolourisation efficiency was mainly due to a generated hydroxyl-radical-related reaction pathway. Possible degradation products from MB oxidation under visible light illumination in the presence of $\mathrm{SrCO}_{3}$ are aromatic sulfonic acids, dimethylamine and phenol, as implied by MS direct injection measurements. Key findings from this work could give more insight into alternative synthesis routes to tailor the bandgap of $\mathrm{SrCO}_{3}$ materials and possible further development of cocatalysts and composites for environmental applications.
\end{abstract}

Keywords: strontium carbonate $\left(\mathrm{SrCO}_{3}\right)$; solvothermal method; photocatalysis; visible light

\section{Introduction}

Textile industries employ over 10,000 dyes and pigments in the manufacturing of cotton, leather, clothes, wool, silk and nylon products [1-3]. An estimated 700,000 tons or more of synthetic dyes are thought to be annually discharged into the environment [4], causing serious water pollution as many of these dyes are toxic, highly water soluble and highly stable against degradation by sunlight or increased temperature [5]. Therefore, effective treatments of dye-contaminated water have continuingly received great attention by academic and industrial sectors. Various wastewater treatment methods have been applied to remove toxic dyes from wastewater, such as coagulation-flocculation, adsorption, membrane separation, biodegradation and oxidation processes [6]. Among these methods, photocatalytic oxidation processes have been proven to be simple and effective at organic dye decomposition, forming relatively 
low toxic by-products with potential mineralization to generate $\mathrm{CO}_{2}$ and $\mathrm{H}_{2} \mathrm{O}$ [7-9]. In this process, under light irradiation a semiconducting catalyst absorbs photon energy promoting electron transfer from the valence band (VB) to the conduction band (CB), resulting in electron-hole pair generation. The generated holes $(\mathrm{h}+)$ further react with water molecules while the electrons $(\mathrm{CB})$ react with oxygen, resulting in formation of active hydroxyl $(\bullet \mathrm{OH})$ and superoxide $\left(\bullet \mathrm{O}_{2}^{-}\right)$radicals, respectively. The $\bullet \mathrm{OH}$ radicals subsequently attack organic pollutants in water leading to oxidative degradation of pollutants.

Wide bandgap $\mathrm{TiO}_{2}$ [10] and $\mathrm{ZnO}$ [11] semiconducting materials have proven to be efficient catalysts for the photo-oxidation of organic pollutants in water. However, these require high-energy ultraviolet irradiation, which requires special and costly safety protocols to be in place for the use of these materials in wastewater treatment. An attractive alternative is to use harmless visible light sources in the photoreactor, employing a visible light responsive photocatalyst for pollutant degradation. Such visible light responsive photocatalysts need to promote the photo-oxidative degradation of pollutants using sunlight ( $7 \%$ UV and $44 \%$ visible light emission, and other low-energy radiations [12]) to ensure wastewater treatment is a sustainable process. Strontium carbonate $\left(\mathrm{SrCO}_{3}\right)$ is a common starting material for the manufacture of colourants in fireworks, glass cathode-ray tubes and computer monitors $[13,14]$. While commercially available $\mathrm{SrCO}_{3}$ material is commonly derived from celestine $\left(\mathrm{SrSO}_{4}\right)$ mineral via calcination followed by $\mathrm{Na}_{2} \mathrm{CO}_{3}$ treatment (the black ash method) [15], synthetic $\mathrm{SrCO}_{3}$ can be obtained using calcination and wet chemical methods under ambient $[16,17]$ or high-pressure [18] atmospheres. Table 1 summarizes the key features (synthesis conditions, characteristics and the bandgap energy) of synthetic $\mathrm{SrCO}_{3}$ in the literature. Methylene blue, a cationic organic dye and a common colouring agent used in cotton, wood, silk [19] cosmetics, and textile [20] dying is a frequently utilized representative dye pollutant mimicking those present in industrial effluents. Song and coworkers reported effective methylene blue (MB) degradation under visible light irradiation $(\lambda>400 \mathrm{~nm})$ after $3 \mathrm{~h}$ treatment with $\mathrm{SrCO}_{3}$ obtained from the calcination of synthetic $\mathrm{Sr}(\mathrm{OH})_{2}$ [21], while Molduvan and coworkers reported the removal of $\mathrm{MB}$ from aqueous solutions using a commercial natural activated plant-based carbon [22]. Other works have utilized $\mathrm{SrCO}_{3}$ as a cocatalyst incorporated in photocatalyst composites, e.g., $\mathrm{Ag}_{2} \mathrm{CO}_{3} / \mathrm{SrCO}_{3}$ [23], $\mathrm{TiO}_{2} / \mathrm{SrCO}_{3}[24]$ and $\mathrm{SrTiO}_{3} / \mathrm{SrCO}_{3}$ [25], to expand the photoresponsive range of the material and to improve its catalytic activity and reaction selectivity.

Table 1. Synthesis, key characteristics and bandgap energy of synthetic $\mathrm{SrCO}_{3}$.

\begin{tabular}{|c|c|c|c|c|}
\hline Conditions & Reaction Time & Morphology & Band Gap & References \\
\hline $\begin{array}{l}\text { Celetine ore }\left(\mathrm{SrSO}_{4}\right) \\
\text { (industrial scale) }\end{array}$ & $\begin{array}{l}\text { Reductive calcination followed by } \\
\mathrm{Na}_{2} \mathrm{CO}_{3}(\mathrm{aq}) \text { assisted precipitation } \\
\text { (the black ash method) }\end{array}$ & - & - & [26] \\
\hline $\begin{array}{l}\text { Celetine ore }\left(\mathrm{SrSO}_{4}\right) \\
\text { (industrial scale) }\end{array}$ & $\begin{array}{l}\text { Double decomposition in } \\
\qquad \mathrm{Na}_{2} \mathrm{CO}_{3}(\mathrm{aq})\end{array}$ & - & - & [27] \\
\hline $\mathrm{Sr}(\mathrm{OH})_{2}+\mathrm{CO}_{2}+\mathrm{EDTA}$ & $50^{\circ} \mathrm{C}, 10 \mathrm{~min}$ & spherical shape & - & {$[28]$} \\
\hline $\mathrm{Sr}\left(\mathrm{NO}_{3}\right)_{2}+\mathrm{TEA}+\mathrm{NaOH}$ & $100^{\circ} \mathrm{C}, 12 \mathrm{~h}$ & branchlet-like $\mathrm{SrCO}_{3}$ nanorods & - & [17] \\
\hline $\mathrm{SrCl}_{2}+\mathrm{H}_{2} \mathrm{O}+\mathrm{DMF}+$ glycerol & $120^{\circ} \mathrm{C}, 8 \mathrm{~h}$ & flower shape & - & [29] \\
\hline $\mathrm{Sr}\left(\mathrm{NO}_{3}\right)_{2}+$ urea & $120^{\circ} \mathrm{C}, 24 \mathrm{~h}$ & urchin-like $\mathrm{SrCO}_{3}$ & - & {$[30]$} \\
\hline $\begin{array}{c}\mathrm{Sr}\left(\mathrm{NO}_{3}\right)_{2}+\left(\mathrm{NH}_{4}\right)_{2} \mathrm{CO}_{3}+ \\
\mathrm{HMT}\end{array}$ & Room temp, 7 days & $\begin{array}{l}\text { branch-like, flower-like, } \\
\text { capsicum-like }\end{array}$ & - & [31] \\
\hline $\begin{array}{l}\mathrm{CH}_{3} \mathrm{COO}_{2} \mathrm{Sr}+\mathrm{Na}_{2} \mathrm{SO}_{4}+ \\
\text { hexamethylene triamine }\end{array}$ & $160^{\circ} \mathrm{C}, 24 \mathrm{~h}$ & spherical shape & 3.17 & {$[32]$} \\
\hline $\mathrm{Sr}\left(\mathrm{NO}_{3}\right)_{2}+\mathrm{Na}_{2} \mathrm{CO}_{3}$ & $120^{\circ} \mathrm{C}, 8 \mathrm{~h}$ & $\begin{array}{l}\text { various shapes such as } \\
\text { rod shape } \\
\text { ellipsoid shape } \\
\text { sphere shape }\end{array}$ & - & [33] \\
\hline $\begin{array}{c}\text { 1. } \mathrm{SrCl}_{2}+\mathrm{Na}_{2} \mathrm{CO}_{3} \\
\text { 2. } \mathrm{SrCl}_{2}+\mathrm{CO}\left(\mathrm{NH}_{2}\right)_{2} \\
\text { 3. } \mathrm{SrCl}_{2}+\mathrm{CO}\left(\mathrm{NH}_{2}\right)_{2}+\mathrm{SDS}\end{array}$ & $\begin{array}{l}\text { 1. } 110^{\circ} \mathrm{C}, 12 \mathrm{~h} \\
\text { 2. } 110^{\circ} \mathrm{C}, 12 \mathrm{~h} \\
\text { 3. } 110^{\circ} \mathrm{C}, 12 \mathrm{~h}\end{array}$ & $\begin{array}{l}\text { rod shape } \\
\text { rod shape } \\
\text { flower shape }\end{array}$ & - & [34] \\
\hline $\mathrm{Sr}(\mathrm{OH})_{2}+$ flowing $\mathrm{CO}_{2}$ gas & $\begin{array}{l}\text { 1. } 50^{\circ} \mathrm{C}, 12 \mathrm{~h} \\
\text { 2. } 60^{\circ} \mathrm{C}, 12 \mathrm{~h} \\
\text { 3. } 70^{\circ} \mathrm{C}, 12 \mathrm{~h}\end{array}$ & $\begin{array}{l}\text { nanowhisker } \\
\text { rod shape } \\
\text { pherical shape }\end{array}$ & - & {$[35]$} \\
\hline
\end{tabular}


This work investigated the effects of precursor concentrations (Sr:ethanol mole ratios), solvothermal temperatures and treatment times on the properties of $\mathrm{SrCO}_{3}$ materials and their photocatalytic degradation of $\mathrm{MB}$ in water under visible light irradiation, as a function of $\mathrm{pH}$ and temperature. Kinetic and mechanistic studies of the MB degradation process were carried out through reaction rate determination and identification of the end-products. The photocatalytic performance of synthesized $\mathrm{SrCO}_{3}$ was compared with that of commercially available material, in order to derive insights into the relationships between properties and catalytic activity.

\section{Results and Discussions}

\subsection{Effects of Synthesis Conditions}

Solvothermal treatments of strontium nitrate in ethanol $(\mathrm{EtOH})$ were carried out at various temperatures $\left(80,100\right.$ and $\left.150{ }^{\circ} \mathrm{C}\right)$, treatment times $(0.5,1,2$ and $3 \mathrm{~h})$ and $\mathrm{Sr}: \mathrm{EtOH}$ mole ratios $(1: 13$, 1:18, 1:23 and 1:27). From powder X-ray diffraction (PXRD) results in Figure 1, a single phase of $\mathrm{SrCO}_{3}$ was obtained from two conditions: $2 \mathrm{~h}$ solvothermal treatment at $100{ }^{\circ} \mathrm{C}$ using a Sr:EtOH mole ratio of $1: 18$ or 1:23. These samples are denoted as $1: 18 \mathrm{SrCO}_{3}$ and 1:23 $\mathrm{SrCO}_{3}$ in further discussions. Notably, mixed phases of $\mathrm{SrCO}_{3}$ and hydrated strontium hydroxides $\left(\mathrm{Sr}(\mathrm{OH})_{2} \cdot \times \mathrm{H}_{2} \mathrm{O}\right.$, where $\mathrm{x}$ is the number of molar coefficient of water in strontium hydroxide solid) were obtained from all other synthesis conditions (results shown in Supplementary Materials: Figures S1 and S2). Typical diffraction peaks correspond well with (110), (111), (021), (002), (012), (130), (220), (221), (132) and (113) orthorhombic $\mathrm{SrCO}_{3}$ lattice planes [34,36], whereas other diffraction peaks match with those of previously reported $\mathrm{Sr}(\mathrm{OH})_{2} \cdot \mathrm{H}_{2} \mathrm{O}$ [37] and $\mathrm{Sr}(\mathrm{OH})_{2} \cdot 8 \mathrm{H}_{2} \mathrm{O}$ phases [38]. The formation of $\mathrm{Sr}(\mathrm{OH})_{2}$ $\mathrm{xH}_{2} \mathrm{O}$ is possibly due to adsorbed alcohol, promoting the addition of $\mathrm{OH}$ functional groups on the solid surface [39], upon solvothermal crystallization of Sr-containing products.

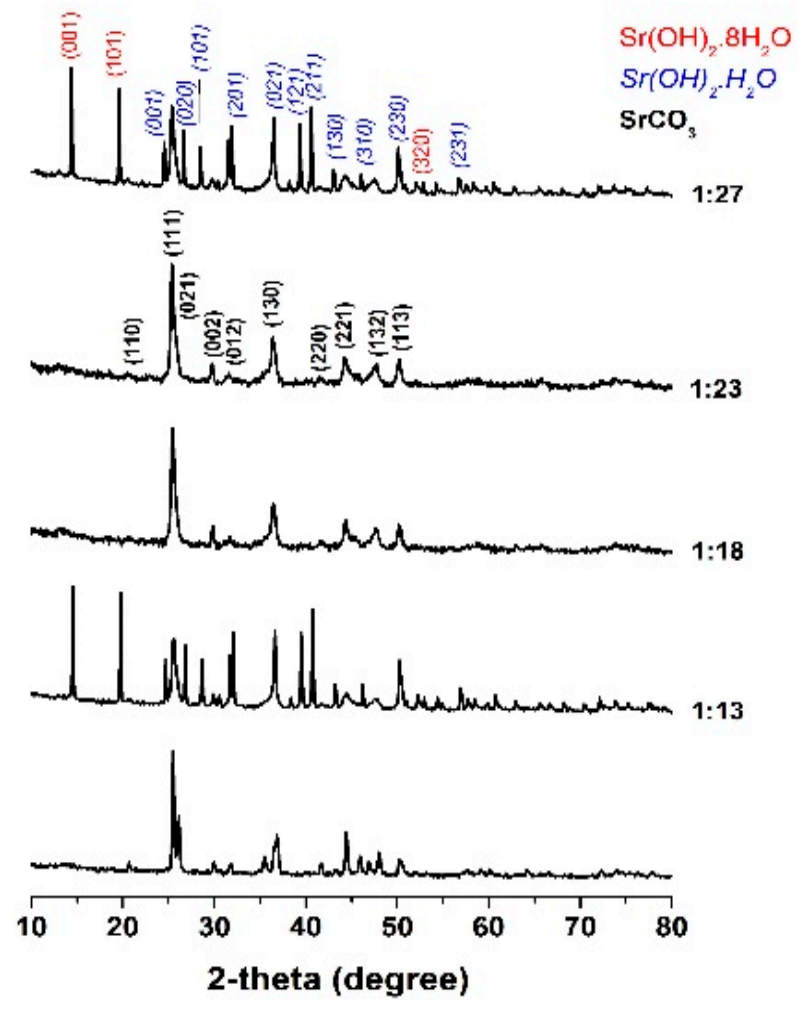

Figure 1. PXRD patterns of Sr-containing samples derived from $2 \mathrm{~h}$ solvothermal treatments of hydrated strontium hydroxide in ethanol at various $\mathrm{Sr}: \mathrm{EtOH}$ mole ratios $\left(1: 13,1: 18,1: 23\right.$ or 1:27) at $100{ }^{\circ} \mathrm{C}$. 
FTIR spectra of the prepared Sr-containing samples are shown in Figure 2. The absorption bands located within $1700-400 \mathrm{~cm}^{-1}$ regions were attributed to the vibrations in $\mathrm{CO}_{3}{ }^{2-}$ groups. The strong broad absorption at $1470 \mathrm{~cm}^{-1}$ was considered to be due to an asymmetric stretching vibration, and the sharp absorption bands at $800 \mathrm{~cm}^{-1}$ and $705 \mathrm{~cm}^{-1}$ can be specified to the bending out-of-plane vibration and in-plane vibration, respectively. The weak peak at $1770 \mathrm{~cm}^{-1}$ indicated a combination of vibration modes of the $\mathrm{CO}_{3}{ }^{2-}$ groups and $\mathrm{Sr}^{2+}$. The sharp peak at $3500 \mathrm{~cm}^{-1}$ was assigned to the stretching mode of $-\mathrm{OH}-$ in $\mathrm{Sr}(\mathrm{OH})_{2}$, and the broad absorption peak around $2800 \mathrm{~cm}^{-1}$ was assigned to the stretching mode of $\mathrm{H}_{2} \mathrm{O}$ in $\mathrm{Sr}(\mathrm{OH})_{2} \cdot \mathrm{H}_{2} \mathrm{O}$ and $\mathrm{Sr}(\mathrm{OH})_{2} \cdot 8 \mathrm{H}_{2} \mathrm{O}$. These results are consistent with the commercial $\mathrm{SrCO}_{3}$ and the 1:18 $\mathrm{SrCO}_{3}$ and 1:23 $\mathrm{SrCO}_{3}$ samples being of similar chemical composition.

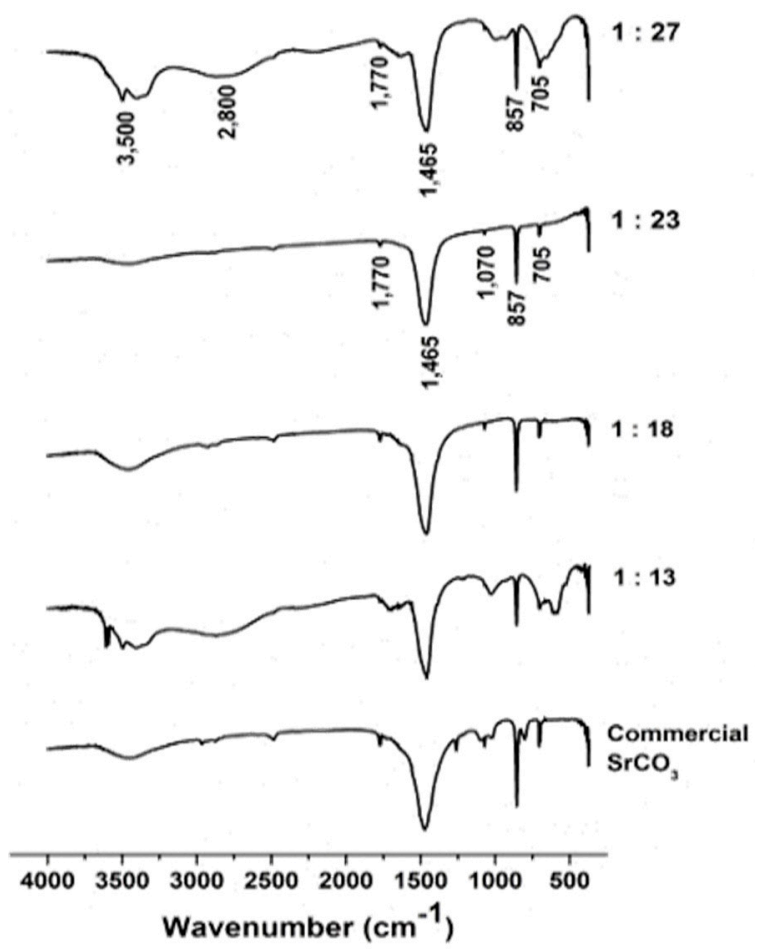

Figure 2. FTIR spectra of Sr-containing samples derived from $2 \mathrm{~h}$ solvothermal treatment of hydrated strontium hydroxide in ethanol at various $\mathrm{Sr}: \mathrm{EtOH}$ mole ratios $\left(1: 13,1: 18,1: 23\right.$ or 1:27) at $100{ }^{\circ} \mathrm{C}$.

SEM images of the obtained $\mathrm{SrCO}_{3}$ materials (derived from Sr:EtOH mole ratios of 1:18 or 1:23) are compared with those of commercial $\mathrm{SrCO}_{3}$ in Figure 3. Whisker-like $\mathrm{SrCO}_{3}$ and spherical particles were obtained under these respective synthesis conditions. Figure $3 \mathrm{c}$ highlights the relatively large rod-like particles of commercial $\mathrm{SrCO}_{3}$. Variation in particle sizes was observed in solvothermally obtained $\mathrm{SrCO}_{3}$, with particle sizes being smaller for the $1: 18 \mathrm{SrCO}_{3}$ samples. Notably, commercial $\mathrm{SrCO}_{3}$ contains much larger particles than those of the synthesized material. From literature [26,27], $\mathrm{SrCO}_{3}$ production plants utilize two common methods, the black ash method and the soda method, in conversion of celestine ore $\left(\mathrm{SrSO}_{4}\right)$ to $\mathrm{SrCO}_{3}$ (Table 1). The black ash method involves high-temperature calcination of the ore to obtain $\mathrm{SrS}$, with crystalline $\mathrm{SrCO}_{3}$ solid being formed after dissolving the SrS in aqueous $\mathrm{Na}_{2} \mathrm{CO}_{3}$, followed by precipitation. The soda method produces $\mathrm{SrCO}_{3}$ through the two-step decomposition reaction between celestine and aqueous $\mathrm{Na}_{2} \mathrm{CO}_{3}$, to obtain precipitated $\mathrm{SrCO}_{3}$. From this information, as the formation of commercial $\mathrm{SrCO}_{3}$ does not require high temperatures $\left(>150{ }^{\circ} \mathrm{C}\right.$ ) for solvent evaporation and precipitation of $\mathrm{SrCO}_{3}$, the larger grain size of the commercial $\mathrm{SrCO}_{3}$ sample is probably due to the fast solvent evaporation during the precipitation processes. 

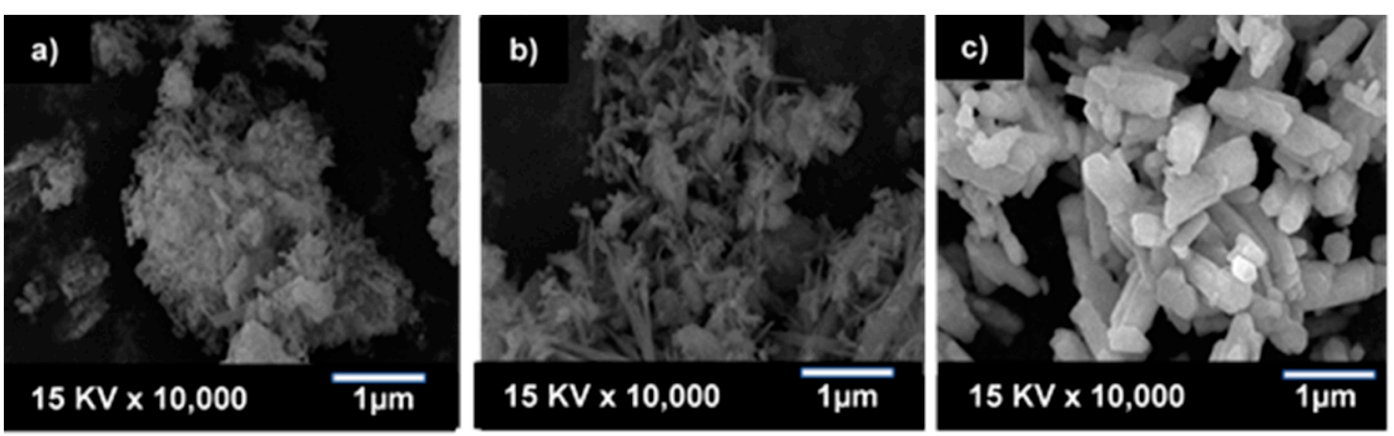

Figure 3. SEM images of $\mathrm{SrCO}_{3}$ derived from $2 \mathrm{~h}$ solvothermal treatment at $100{ }^{\circ} \mathrm{C}$, using $\mathrm{Sr}: \mathrm{EtOH}$ mole ratios of (a) 1:18 and (b) 1:23 compared with (c) commercial $\mathrm{SrCO}_{3}$.

Thermogravimetric analysis (TGA) plots (Figure 4) suggest thermal stability of all $\mathrm{SrCO}_{3}$ samples up to $600{ }^{\circ} \mathrm{C}$. Slight weight loss $(<1 \%)$ was likely due to moisture or solvent residue [40]. The 1:23 $\mathrm{SrCO}_{3}$ sample gives a relatively high weight loss of $0.21 \%$, which corresponds to the removal of surface adsorbed moisture and ethanol (weight loss upon heating up to $400^{\circ} \mathrm{C}$ ) and the loss of ethanol from the $\mathrm{SrCO}_{3}$ lattice at ca. $450{ }^{\circ} \mathrm{C}$. Decomposition of $\mathrm{SrCO}_{3}$ takes place at temperatures above $800{ }^{\circ} \mathrm{C}$ as a result of conversion to $\mathrm{SrO}$.

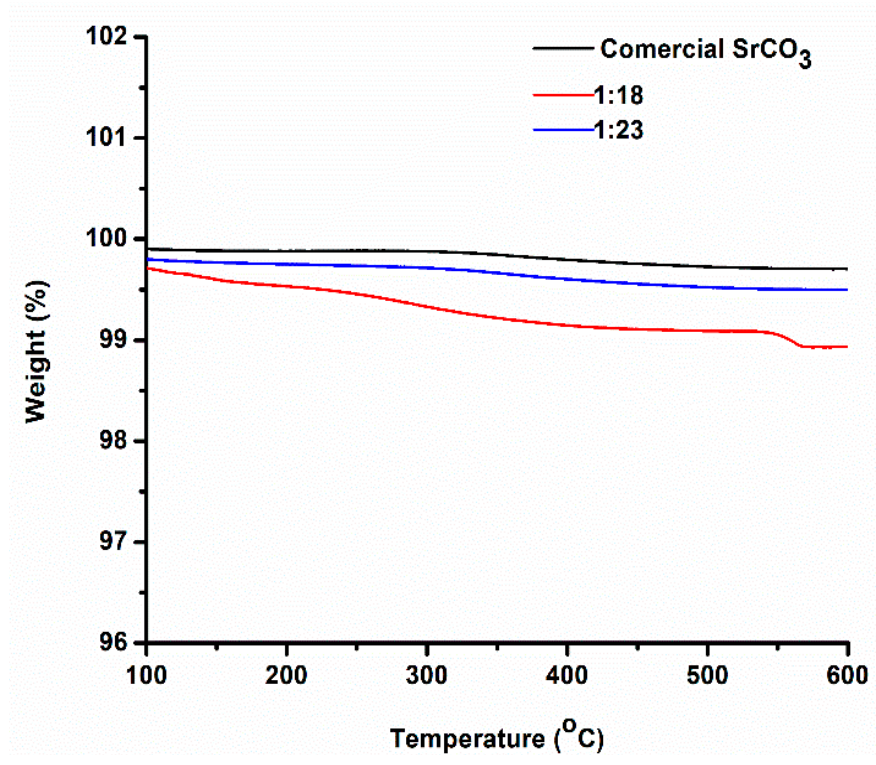

Figure 4. Thermogravimetric analysis (TGA) plots of $\mathrm{SrCO}_{3}$ samples prepared using Sr:EtOH mole ratios of 1:18 and 1:23, compared with that of commercial $\mathrm{SrCO}_{3}$.

Based on the PXRD and TGA results, chemical transformation of hydrated strontium hydroxide in the presence of ethanol under solvothermal treatments leads to the formation of $\mathrm{SrCO}_{3}$ and ethanol incorporated $\mathrm{SrCO}_{3}$ materials, as proposed by the reactions below. In general, $\mathrm{CO}_{2}$ in air can react with strontium hydroxide to form $\mathrm{SrCO}_{3}$, which precipitates after the sonication step and solvothermal treatments. Ethoxide could be formed under basic conditions, resulting in an $\mathrm{CH}_{3} \mathrm{CH}_{2} \mathrm{O} \cdots \mathrm{Sr}^{2+} \ldots \mathrm{OCH}_{2} \mathrm{CH}_{3}$ intermediate, which is subsequently transformed to ethanol incorporated in $\mathrm{SrCO}_{3}$. Note that the amount of ethanol incorporated within the $\mathrm{SrCO}_{3}$ is sufficiently low, such that a single phase of $\mathrm{SrCO}_{3}$ was observed in PXRD pattern of the 1:23 $\mathrm{SrCO}_{3}$ sample.

$$
\begin{gathered}
\mathrm{Sr}(\mathrm{OH})_{2}+\mathrm{CO}_{2} \rightarrow \mathrm{SrCO}_{3}+\mathrm{H}_{2} \mathrm{O} \\
\mathrm{Sr}(\mathrm{OH})_{2}+\mathrm{CO}_{2} \rightleftharpoons \mathrm{Sr}^{2+}+\mathrm{HCO}_{3}^{-}+\mathrm{OH}^{-}
\end{gathered}
$$




$$
\begin{gathered}
\mathrm{HCO}_{3}{ }^{-}+\mathrm{OH}^{-} \rightarrow \mathrm{CO}_{3}^{2-}+\mathrm{H}_{2} \mathrm{O} \\
\mathrm{CH}_{3} \mathrm{CH}_{2} \mathrm{OH}+\mathrm{OH}^{-} \rightleftharpoons \mathrm{CH}_{3} \mathrm{CH}_{2} \mathrm{O}^{-}+\mathrm{H}_{2} \mathrm{O} \\
\mathrm{Sr}(\mathrm{OH})_{2}+\mathrm{H}_{2} \mathrm{O} \rightleftharpoons \mathrm{Sr}^{2+}(\mathrm{aq})+\mathrm{OH}^{-}(\mathrm{aq}) \\
\mathrm{Sr}^{2+}+2 \mathrm{CH}_{3} \mathrm{CH}_{2} \mathrm{O}^{-} \rightarrow \mathrm{Sr}^{2+} \ldots 2 \mathrm{OCH}_{2} \mathrm{CH}_{3} \\
\mathrm{Sr}^{2+} \ldots \mathrm{OCH}_{2} \mathrm{CH}_{3}+\mathrm{HCO}_{3}{ }^{-} \rightarrow \mathrm{SrCO}_{3} \cdots \mathrm{HOCH}_{2} \mathrm{CH}_{3}
\end{gathered}
$$

\subsection{Optical Properties}

UV-VIS diffuse reflectance spectra of the 1:18 $\mathrm{SrCO}_{3}, 1: 23 \mathrm{SrCO}_{3}$ and commercial $\mathrm{SrCO}_{3}$ in Figure 5a showed that the characteristic absorption edge of the $1: 23 \mathrm{SrCO}_{3}$ sample is located in the visible light region $(473 \mathrm{~nm})$, whereas the spectral response of other $\mathrm{SrCO}_{3}$ samples was observed in the UV region, with absorption band edges of 268 and $381 \mathrm{~nm}$ for the 1:18 $\mathrm{SrCO}_{3}$ sample and commercial $\mathrm{SrCO}_{3}$, respectively. The band gap energy values suggested by Kubelka-Munk plots (Figure 5b) are 4.63 and $3.25 \mathrm{eV}$ for 1:18 $\mathrm{SrCO}_{3}$ and commercial $\mathrm{SrCO}_{3}$, respectively. By contrast, the bandgap energy of the 1:23 $\mathrm{SrCO}_{3}$ sample is $2.62 \mathrm{eV}$, and its visible response is possibly due to the presence of incorporated ethanol in the solid sample, as suggested by TGA results.
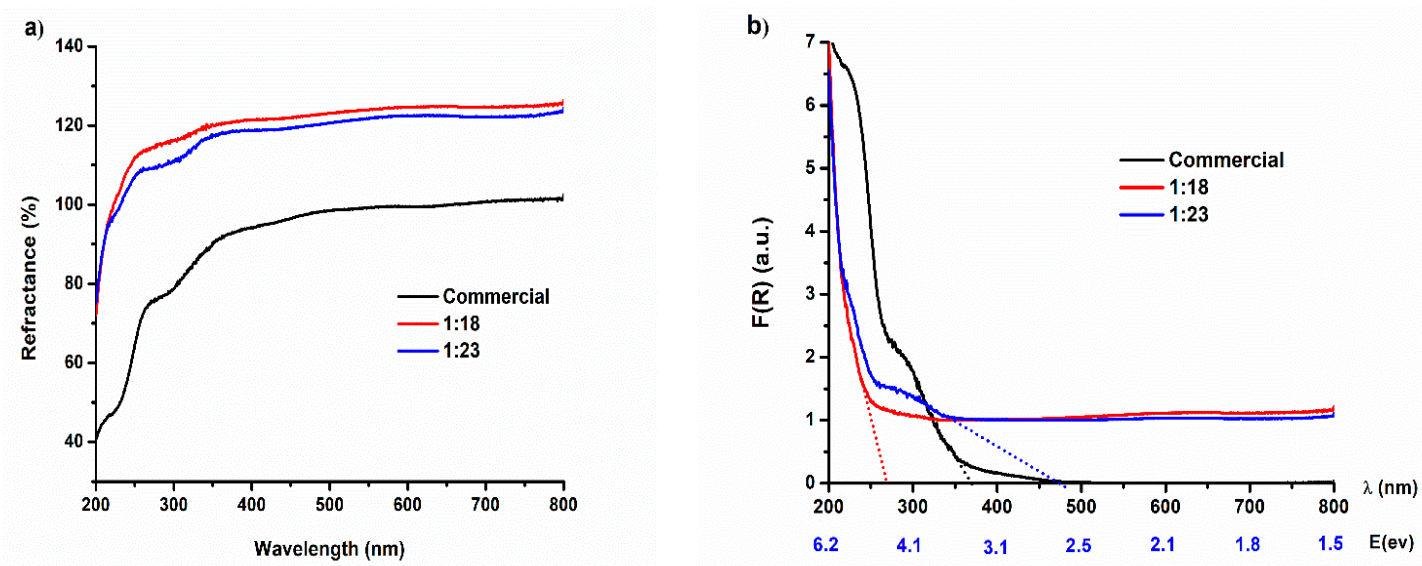

Figure 5. (a) UV-visible diffuse reflectance spectra and (b) Kubelka-Munk plots of the $\mathrm{SrCO}_{3}$ synthesized at Sr:EtOH mole ratios of 1:18 and 1:23, compared with those of commercial $\mathrm{SrCO}_{3}$.

\subsection{Decolourisation of Methylene Blue (MB)}

Figure 6a illustrates the colour removal efficiencies of $10 \mathrm{ppm} \mathrm{MB}$ aqueous solutions in the dark and under visible light irradiation after $1 \mathrm{~h}$ treatment with $\mathrm{SrCO}_{3}$. Similar colour removal efficiencies from treatment of $\mathrm{MB}(\mathrm{aq})$ with $1: 18 \mathrm{SrCO}_{3}$ in the dark and under light illumination suggested major adsorption processes occurred due to the wide bandgap of the 1:18 $\mathrm{SrCO}_{3}$ sample. On the other hand, the visible responsive 1:23 $\mathrm{SrCO}_{3}$ and commercial $\mathrm{SrCO}_{3}$ gave higher colour removal efficiencies under irradiation conditions than those from dark experiments, implying both adsorption and photodegradation of MB are of importance. Therefore, from these catalyst screening tests, the colour removal efficiencies of aqueous $\mathrm{MB}$ solutions strongly depend on the bandgap energy of $\mathrm{SrCO}_{3}$ materials and that the $1: 23 \mathrm{SrCO}_{3}$ is the most active catalyst. Figure $6 \mathrm{~b}$ demonstrates that only low colour removal efficiencies occur due to adsorption (in the dark) and photolysis (irradiation and no $\mathrm{SrCO}_{3}$ ). Treatments of dye solutions with 1:23 $\mathrm{SrCO}_{3}$ is much less effective (low colour removal efficiency) under dark conditions in comparison to decolourisation under visible light irradiation. These results suggest that the main process of $\mathrm{MB}$ colour removal is caused by photocatalytic treatment by using the $\mathrm{SrCO}_{3}$ photocatalyst rather than adsorption. 
a)

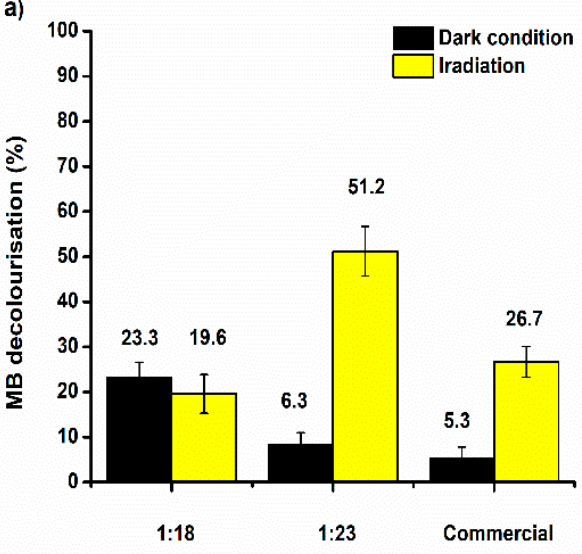

b)

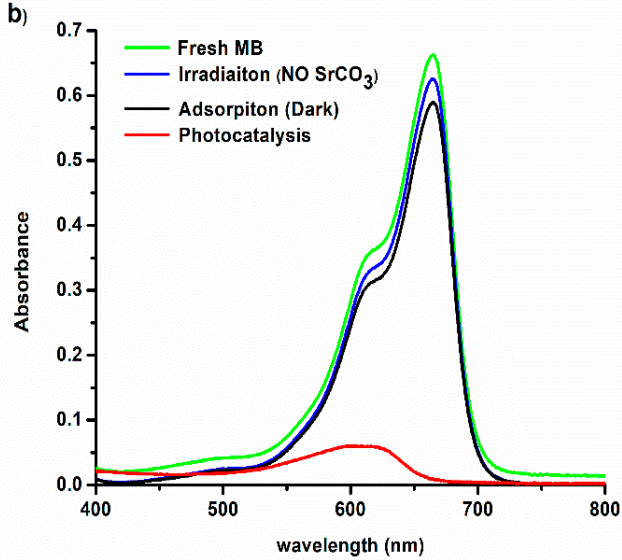

Figure 6. (a) Colour removal efficiencies of $10 \mathrm{ppm}$ methylene blue (MB) aqueous solution in the dark, and under visible light irradiation in the presence of $\mathrm{SrCO}_{3}$. (b) Absorption spectra of $\mathrm{MB}$ in the dark or under visible light irradiation by $\mathrm{SrCO}_{3}$ (1:23 and 1:18). All decolourisation experiments were performed at $30{ }^{\circ} \mathrm{C}$ using $\mathrm{SrCO}_{3}$ with catalyst loadings of $4.0 \mathrm{~g} \cdot \mathrm{L}^{-1}$ with $1 \mathrm{~h}$ treatment.

The percentage of $\mathrm{MB}$ colour removal after treatment with $\mathrm{SrCO}_{3}$ photocatalyst (sample 1:23) is shown in Figure 7a. When a suspension of $\mathrm{SrCO}_{3}$ in $10 \mathrm{ppm}$ fresh $\mathrm{MB}$ solution was kept in the dark for $3 \mathrm{~h}$, the concentration of dye slightly decreased, while the colour of the dye solution remained unchanged. It was observed that the absorption capacity of $\mathrm{MB}$ on the $\mathrm{SrCO}_{3}$ surface is negligible because the specific area of the prepared $\mathrm{SrCO}_{3}$ photocatalyst is low $\left(9.23 \mathrm{~m}^{2} \cdot \mathrm{g}^{-1}\right)$. Upon visible irradiation, the prepared $\mathrm{SrCO}_{3}$ gave a high percentage of $\mathrm{MB}$ colour removal $(>99 \%$ after $3 \mathrm{~h}$ visible irradiation).
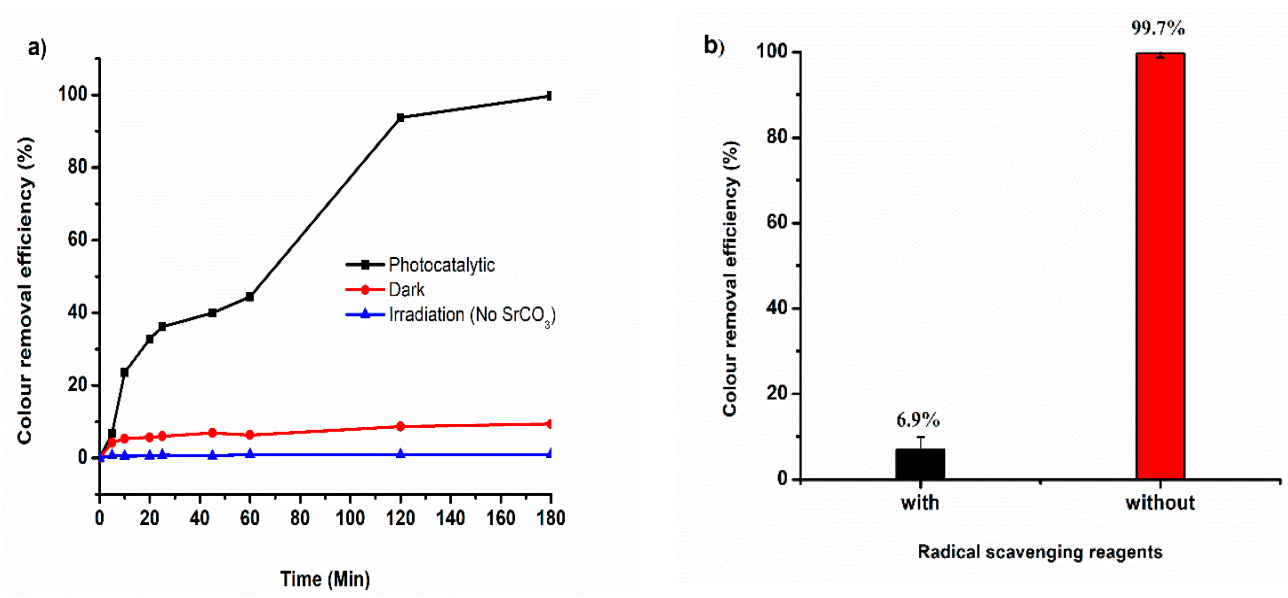

Figure 7. (a) Colour removal efficiencies of $10 \mathrm{ppm} \mathrm{MB}$ aqueous solution (pH 5.5) as a function of time in the dark or under visible light irradiation; adsorption of $\mathrm{MB}$ into $\mathrm{SrCO}_{3}$ (loading $4 \mathrm{~g} \cdot \mathrm{L}^{-1}$ ) in the dark, $\mathrm{MB}$ photolysis and photocatalysis of $\mathrm{MB}$ under visible light illumination catalyzed by $\mathrm{SrCO}_{3}$ (loading $\left.4 \mathrm{~g} \cdot \mathrm{L}^{-1}\right)$. (b) Effects of a scavenger (tert-BuOH) on the colour removal efficiency of $10 \mathrm{ppm} \mathrm{MB}$ after $3 \mathrm{~h}$ treatment with the $1: 23 \mathrm{SrCO}_{3}\left(4 \mathrm{~g} \cdot \mathrm{L}^{-1}\right)$.

In order to prove that hydroxyl radicals $(\bullet \mathrm{OH})$ are the active species in the photocatalytic degradation process, experiments were conducted in the presence of a radical scavenging reagent. One such reagent, tert-butyl alcohol (tert- $\mathrm{BuOH}$ ), if present, should significantly inhibit the oxidation of MB [41]. The result in Figure $7 \mathrm{~b}$ indicates that after treatment for $3 \mathrm{~h}$, adding tert- $\mathrm{BuOH}$ resulted in poor colour removal efficiencies $(6.90 \%)$, whereas in the absence of the reagent very high colour removal efficiencies $(>99 \%)$ were achieved. The formation of a product arising from the reaction 
between tert- $\mathrm{BuOH}$ and $\bullet \mathrm{OH}$ as ascribed through a radical pathway [41] thus resulted in the poor activity, confirming that hydroxyl radicals are the important active species assisting MB degradation.

The effect of $\mathrm{pH}$ on the $\mathrm{MB}$ decolourisation under visible light irradiation was examined over a range of $\mathrm{pH} 3-9$. The colour removal efficiency reached $73 \%$ after $1 \mathrm{~h}$ treatment at $\mathrm{pH} 3$, while lower colour removal efficiencies were obtained at $\mathrm{pH} 5.5(51 \%), \mathrm{pH} 7(42 \%)$ and $\mathrm{pH} 9(29 \%)$ over the same time period, as shown in Figure 8a. In addition, the natural logarithm of the MB concentrations was plotted as a function of irradiation time, affording a linear relationship, as presented in Figure $8 \mathrm{~b}$. Using the first-order model, the highest rate constant of $\mathrm{MB}$ colour removal was obtained at $\mathrm{pH} 3$, with the degradation being slowest at $\mathrm{pH}$ 9. The decreasing rate constants of $\mathrm{MB}$ decolourisation with increasing $\mathrm{pH}$ may be the result of the presence of carbonate $\left(\mathrm{CO}_{3}{ }^{2-}\right)$ and hydroxide $\left(\mathrm{OH}^{-}\right)$ions, which are radical scavengers [42,43]. At $\mathrm{pH}$ 5.5-10, the low colour removal efficiencies may be due to the following reactions.

$$
\begin{gathered}
\mathrm{CO}_{3}^{2-}+\bullet \mathrm{OH} \rightarrow \mathrm{CO}_{3}^{\bullet-}+\mathrm{OH}^{-} \\
\mathrm{OH}^{-}+\bullet \mathrm{OH} \rightarrow \mathrm{H}_{2} \mathrm{O}+\mathrm{O}^{-}
\end{gathered}
$$
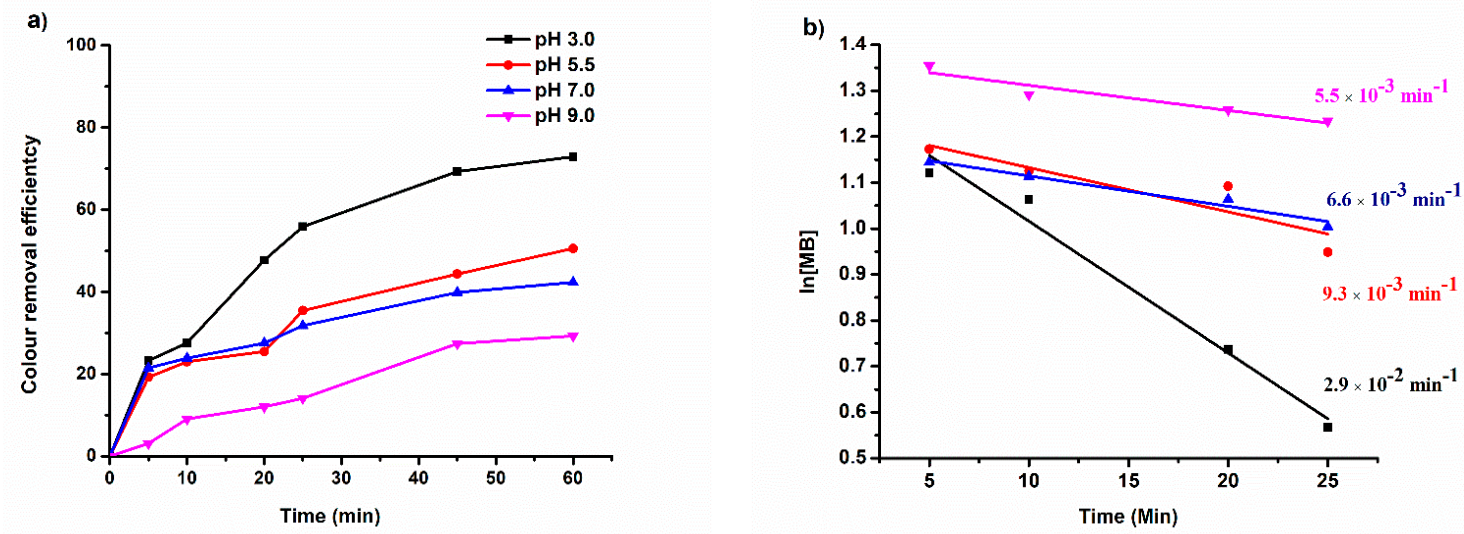

Figure 8. (a) Colour removal efficiencies of $10 \mathrm{ppm} \mathrm{MB}$ aqueous solution with time, using $\mathrm{SrCO}_{3}$ as photocatalyst. (b) Kinetics of $\mathrm{MB}$ decolourisation catalyzed by $\mathrm{SrCO}_{3}$ as a function of $\mathrm{pH}$. All decolourisation experiments were performed using $\mathrm{SrCO}_{3}$ with catalyst loading of $4.0 \mathrm{~g} \cdot \mathrm{L}^{-1}$ at $30{ }^{\circ} \mathrm{C}$ from $\mathrm{pH} 3-9$.

The effect of temperature on the degradation of $\mathrm{MB}$ as a function of time is discussed in Figure 9. From Figure 9a, it can be observed that higher temperatures result in higher MB colour removal efficiencies. Under visible light irradiation, the MB colour removal efficiency reached $100 \%$ after $1 \mathrm{~h}$ treatment at $70{ }^{\circ} \mathrm{C}$. In all cases $\mathrm{MB}$ concentrations decrease with irradiation time. The linear plots between the natural logarithm of the $\mathrm{MB}$ concentration versus irradiation time are shown in Figure $9 \mathrm{~b}$, which indicate that the decolourisation process follows first-order kinetics. The rate constants of $\mathrm{MB}$ decolourisation increased with temperature, indicating that $\mathrm{MB}$ removal by $1: 23 \mathrm{SrCO}_{3}$ is overall endothermic. The 1:23 $\mathrm{SrCO}_{3}$ sample is rather stable during the photocatalytic MB degradation reaction, as only negligible concentrations of $\mathrm{Sr}(<10 \mathrm{ppm})$ were detected in the treated MB solution. 

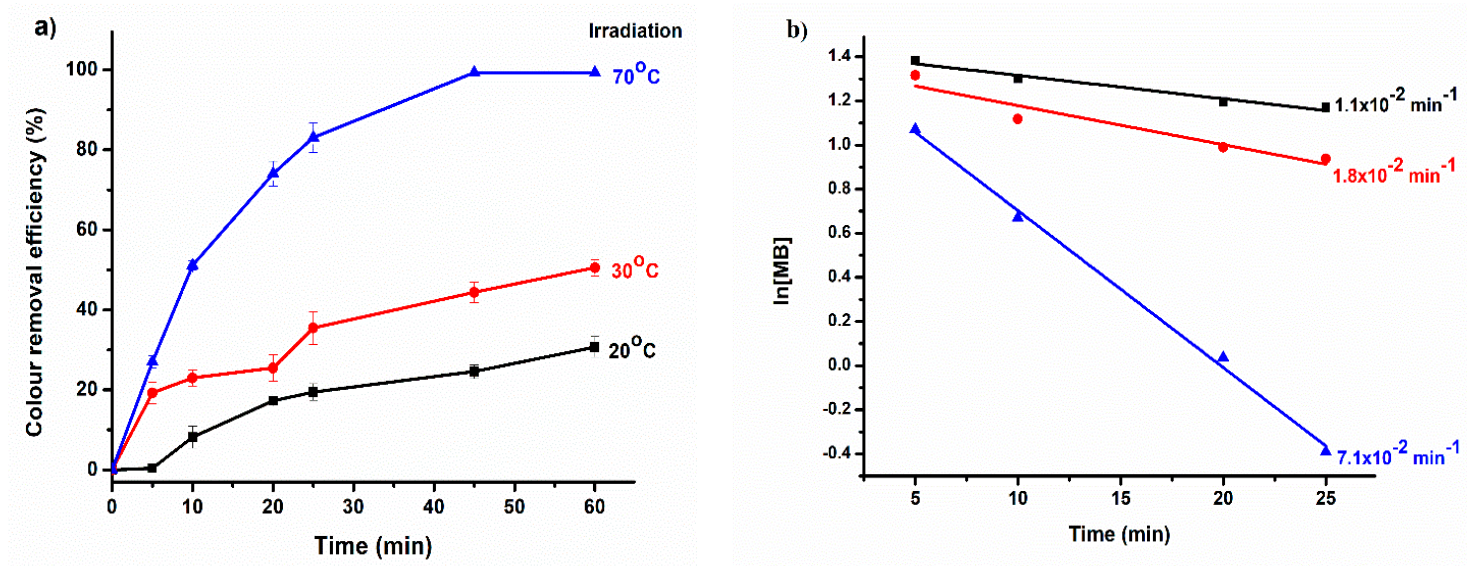

Figure 9. (a) Colour removal efficiencies of $10 \mathrm{ppm} \mathrm{MB}$ aqueous solution (pH 5.5) over time using $\mathrm{SrCO}_{3}$ as photocatalyst. (b) Kinetics of $\mathrm{MB}$ decolourisation catalyzed by $\mathrm{SrCO}_{3}$ as a function of temperature. All decolourisation experiments were performed using 1:23 $\mathrm{SrCO}_{3}$ with catalyst loading of $4.0 \mathrm{~g} \cdot \mathrm{L}^{-1}$ at temperatures $20-70{ }^{\circ} \mathrm{C}$.

\subsection{Degradation Products}

Figure 10 highlights mass spectra generated from the MB degradation products with the mass-to-charge ratios (m/z) of 77, 122, 234, 284 and 303, reported with the possible fragmented ions shown accordingly.

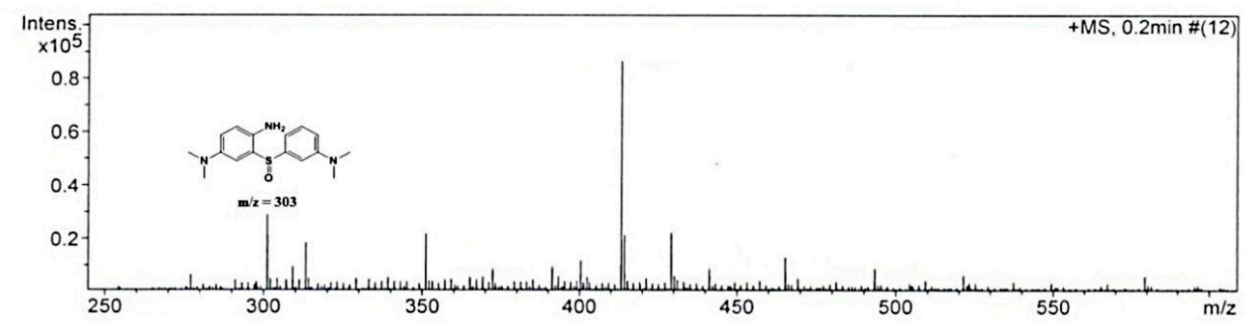

(a)

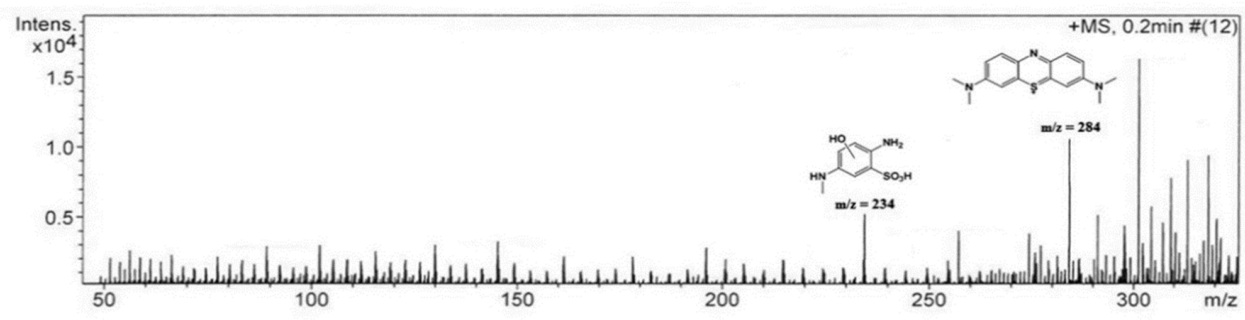

(b)

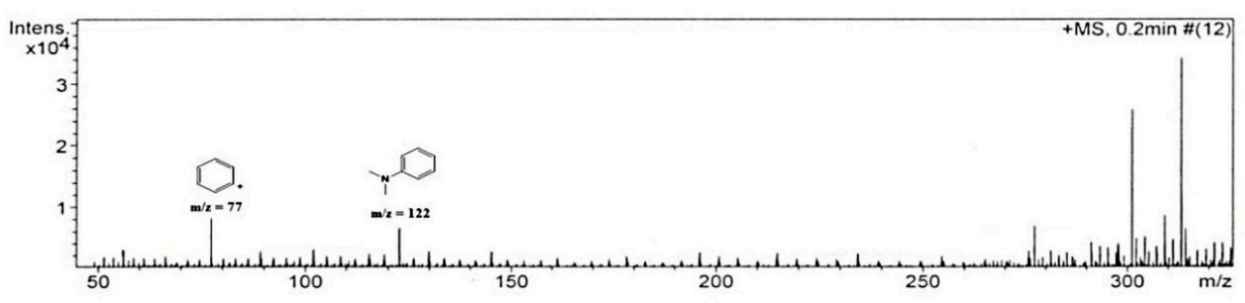

(c)

Figure 10. Mass spectra of intermediates from the MB degradation after treatment for (a) $10 \mathrm{~min}$, (b) $25 \mathrm{~min}$ and (c) $60 \mathrm{~min}$. All experiments were performed by suspending 1:23 $\mathrm{SrCO}_{3}$ in $10 \mathrm{ppm} \mathrm{MB}$ (4 g. $\mathrm{L}^{-1}$ of $\mathrm{MB}$ solution) followed by visible light illumination. 
The proposed reaction pathway of $\mathrm{MB}$ photooxidation over $\mathrm{SrCO}_{3}$ photocatalyst is outlined in Figure 11. The detected degradation products, as identified from fragments based on $\mathrm{m} / \mathrm{z}$ ratio, are illustrated in blue, while undetectable but expected intermediates $[44,45]$ are presented in black. These results are in general agreement with previous works that report the generated intermediates during the MB photodegradation process [44,45].

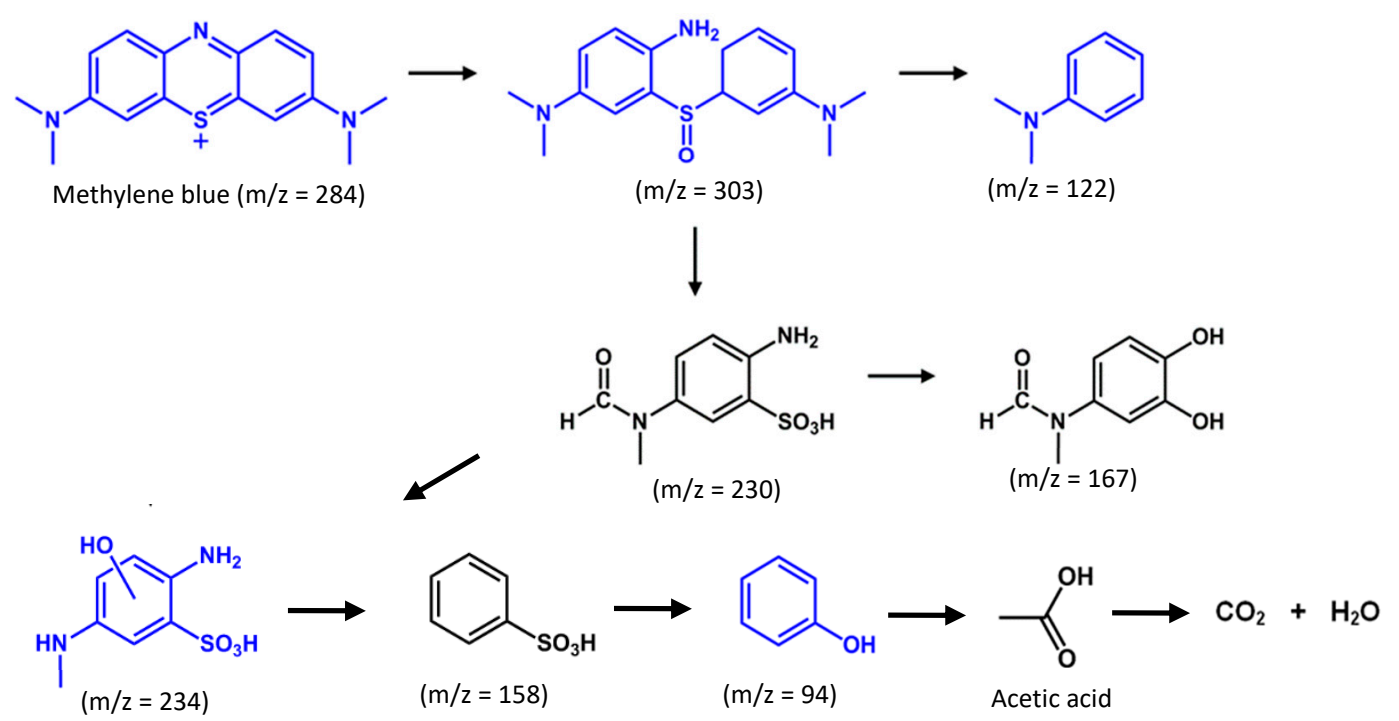

Figure 11. Proposed photocatalytic degradation pathway of MB. Detected degradation products are illustrated in blue, while expected but undetectable [44] species are presented in black.

\section{Materials and Methods}

\subsection{Chemicals}

All reagents were used without further purification. Chemicals of HPLC grade were acetic acid $\left(\mathrm{C}_{2} \mathrm{H}_{3} \mathrm{O}_{2}\right.$, Merck, Darmstadt, Germany) and acetonitrile $\left(\mathrm{C}_{2} \mathrm{H}_{2} \mathrm{~N}\right.$, J.T. Baker, CA, USA). Chemicals of AR grade were ethanol $\left(\mathrm{C}_{2} \mathrm{H}_{5} \mathrm{OH}\right.$, Merck, Germany), potassium bromide ( $\mathrm{KBr}$, Merck, Germany), tert-butanol $\left(\mathrm{C}_{4} \mathrm{H}_{10} \mathrm{O}\right.$, Merck, Germany), ammonium acetate $\left(\mathrm{C}_{2} \mathrm{H}_{2} \mathrm{ONH}_{4}\right.$, Rankem, Gurugram, India), sodium hydroxide $\left(\mathrm{NaOH}\right.$, Rankem, India), methylene blue $\left(\mathrm{C}_{16} \mathrm{H}_{18} \mathrm{~N}_{3} \mathrm{Cl}\right.$, Fluka, Saint Louis, $\mathrm{MO}$, USA), strontium carbonate $\left(\mathrm{SrCO}_{3}\right.$, Fluka, USA), concentrated hydrochloric acid ( $\mathrm{HCl}, \mathrm{Lab} \mathrm{Scan}$, Ireland), mercury(II) sulphate $\left(\mathrm{HgSO}_{4}\right.$, QRëc, Newzaland), nitric acid $\left(\mathrm{HNO}_{3}\right.$, Mallinckrodt Chemicals, Phillipsburg, NJ, USA), potassium dichromate $\left(\mathrm{K}_{2} \mathrm{Cr}_{2} \mathrm{O}_{7}\right.$, Unilab, Mandaluyong, Philippines), potassium hydrogen phthalate $\left(\mathrm{C}_{8} \mathrm{H}_{5} \mathrm{KO}_{4}\right.$, Univar, Redmond to Downers Grove, IL, USA), silver sulphate $\left(\mathrm{AgSO}_{4}\right.$, Carlo Erba, Barcelona, Spain), strontium hydroxide octahydrate $\left(\mathrm{Sr}(\mathrm{OH})_{2} \cdot 8 \mathrm{H}_{2} \mathrm{O}\right.$, Sigma Aldrich, Saint Louis, MO, USA) and concentrated sulfuric acid $\left(\mathrm{H}_{2} \mathrm{SO}_{4}\right.$, Lab supplies, Spain).

\subsection{Synthesis of Strontium Carbonate $\left(\mathrm{SrCO}_{3}\right)$}

Strontium carbonate $\left(\mathrm{SrCO}_{3}\right)$ was synthesized by a solvothermal method modified from the procedure of Zhang et al. [34]. A suspension of $20 \mathrm{~g} \mathrm{Sr}(\mathrm{OH})_{2} \cdot 8 \mathrm{H}_{2} \mathrm{O}$ in ethanol $(100 \mathrm{~mL})$ was sonicated in an ultrasonic bath for $20 \mathrm{~min}$, followed by solvothermal treatment in an autoclave at 80, 100, 120 or $150^{\circ} \mathrm{C}$ for $2 \mathrm{~h}$. The reaction mixtures were left at room temperature to cool down to room temperature. Then, the precipitates were washed with deionized water to remove $\mathrm{Sr}(\mathrm{OH})_{2} \cdot \mathrm{xH}_{2} \mathrm{O}$, dried and kept in a dry condition at room temperature. After obtaining the optimal treatment temperature, the reaction time was investigated through the above procedure by fixing the treatment temperature at $100{ }^{\circ} \mathrm{C}$ and varying reaction time between $0.5,1,2$ or $3 \mathrm{~h}$. The strontium-based samples were prepared by varying the $\mathrm{Sr}(\mathrm{OH})_{2} \cdot 8 \mathrm{H}_{2} \mathrm{O}$ : ethanol mole ratio as either $1: 13,1: 18,1: 23$ or $1: 27$, and then the above procedures were followed using a treatment temperature of $100^{\circ} \mathrm{C}$ for $2 \mathrm{~h}$. 


\subsection{Materials Characterisation}

The crystallinity and the phase structure of the samples were investigated using X-ray diffractometry (PXRD, Bruker AXS model D8 advance). The measurements were examined with CuK $\alpha$ radiation between $2 \theta$ values of $10-80$ degrees, at a scan rate of 0.075 degree. $\mathrm{min}^{-1}$ using accelerating voltage and currents of $40 \mathrm{kV}$ and $40 \mathrm{~mA}$, respectively. Chemical composition and bonding information were probed using Fourier transform infrared spectrophotometry (FT-IR, Elmer model lamda 800). Diffusion reflectance spectra were measured on a UV-VIS spectrophotometer (Agilent Cary 5000) using a scanning rate of 200-1100 nm. Sample morphologies were investigated using scanning electron microscopy (SEM). The thermal decomposition of $\mathrm{SrCO}_{3}$ was monitored using a thermogravimetric analyzer (TGA, TA instruments SDT 2960 Simultaneous DSC-TGA).

\subsection{Catalyst Performance Examinations}

$\mathrm{SrCO}_{3}$ samples were dispersed in $10 \mathrm{~mL}$ of $10 \mathrm{ppm} \mathrm{MB}$ aqueous solution in order to observe the change in colour under dark and visible light irradiation conditions. Before illumination, the suspensions were stirred in the dark for $5 \mathrm{~min}$. Then, suspensions were irradiated using an LED $(16 \times 12 \mathrm{~V}$ EnduraLED $10 \mathrm{~W}$ MR16 dimmable $4000 \mathrm{~K}$ with $\lambda>400 \mathrm{~nm})$ [46]. The colour removal efficiency of MB was monitored as a function of degradation time by measuring the absorbance of the dye solution after treatment. In order to terminate the reaction, the photocatalyst was filtered off using a syringe filter $(0.45 \mu \mathrm{m})$. The absorbance of the dye was then measured, and the concentration of remaining $\mathrm{MB}$ was quantified using the absorbance at maximum wavelength (around $664.5 \mathrm{~nm}$ ) using the Beer Lambert law.

The colour removal efficiency of MB was calculated via Equation (1):

$$
\text { Colour removal efficiency }=\left(\frac{C_{0}-C_{t}}{C_{0}}\right) \times 10
$$

where $C_{0}$ is the concentration of fresh $\mathrm{MB}$ solution, and $C_{t}$ is the concentration of dye residue after treatment at $t$ minutes.

Leaching of strontium ions may be a major cause of photocatalyst deactivation. Therefore, the amount of strontium ions in the filtered MB solution was quantified by flame atomic absorption spectrometry (FAAS, Perkin Elmer, Waltham, MA, USA).

A mass spectrometer (micro TOF MS, Bruker, Billerica, MA, USA) equipped with electrospray ionization (ESI) source was employed to detect MB degradation products. For this, direct injection of the treated $\mathrm{MB}$ solution (with 1:23 $\mathrm{SrCO}_{3}$ ) under visible light irradiation was carried out, with fragments examined over the range $\mathrm{m} / \mathrm{z} 50-700$.

\section{Conclusions}

In this work, a solvothermal method without any calcination step was employed to prepare a single crystalline phase of strontium carbonate $\left(\mathrm{SrCO}_{3}\right)$. Ethanol incorporated $\mathrm{SrCO}_{3}$, a visible light responsive $\mathrm{SrCO}_{3}$ material having a bandgap energy of $2.62 \mathrm{eV}$, was obtained from the solvothermal treatment of hydrated strontium hydroxide in ethanol at $\mathrm{Sr}: \mathrm{EtOH}$ of 1:23. Nevertheless, the synthesis conditions strongly influence the bandgap energy of $\mathrm{SrCO}_{3}$, as $\mathrm{UV}$ responsive $\mathrm{SrCO}_{3}$ material can also be obtained by varying the precursor concentration. The narrow bandgap $\mathrm{SrCO}_{3}$ material can be utilized as a photocatalyst for decolourisation of methylene blue in water under visible light irradiation. Effective decolourisation of $10 \mathrm{ppm}$ methylene blue aqueous solutions was achieved with $>99 \%$ colour removal efficiencies after $3 \mathrm{~h}$ treatment, under visible light irradiation over the 1:23 photocatalyst, using a catalyst loading of $4 \mathrm{~g} \cdot \mathrm{L}^{-1}$. The decolourisation is mainly due to photocatalytic processes. The rate constant values showed a direct correlation with temperature, but decolourisation was most rapid at low $\mathrm{pH}$. In addition to the conventional uses of $\mathrm{SrCO}_{3}$ in pyrotechnics and frit manufacturing, synthesized $\mathrm{SrCO}_{3}$ materials have their place as semiconductors and cocatalysts employed in energy 
and environmental applications. The key findings of this work highlight that incorporated ethanol in the $\mathrm{SrCO}_{3}$ structure results in a narrowing of the energy bandgap in $\mathrm{SrCO}_{3}$, with the material being a visible light responsive semiconductor and active photocatalyst in dye degradation. Results from this work may suggest alternative synthesis routes to obtain visible responsive $\mathrm{SrCO}_{3}$ materials, for further development of new composites and cocatalysts in broader applications.

Supplementary Materials: The following are available online at http://www.mdpi.com/2073-4344/10/9/1069/s1. Figure S1: PXRD patterns of Sr-containing samples derived from solvothermal treatments of hydrated strontium hydroxide in ethanol (a) at various solvothermal temperatures, $2 \mathrm{~h}$, Sr:EtOH mole ratios of 1:23 and (b) at various solvothermal treatment times, $100{ }^{\circ} \mathrm{C}$, Sr:EtOH mole ratios of 1:23; Figure S2: FTIR spectra of Sr-containing samples derived from solvothermal treatment of hydrated strontium hydroxide in ethanol (a) at various solvothermal temperatures, $2 \mathrm{~h}$, Sr:EtOH mole ratios of 1:23 and (b) at various solvothermal treatment times, $100{ }^{\circ} \mathrm{C}, \mathrm{Sr}: \mathrm{EtOH}$ mole ratios of 1:23.

Author Contributions: Formal acquisition, investigation and writing-original draft, P.W. writing-review, editing, T.K.; funding acquisition, writing-review, editing and supervision, S.M.S. All authors have read and agreed to the published version of the manuscript.

Funding: M.Sc. Student scholarship (for P.W.) was provided by the Center of Excellence for Innovation in Chemistry (PERCH-CIC). This work was partially supported by the Thailand Research Fund (Grant No. RSA5980027 and IRN62W0005) for T.K. and S.M.S., the National Research Council of Thailand for P.W, and by the CIF, Faculty of Science, Mahidol University.

Acknowledgments: The authors are grateful for partial financial support from the Thailand Research Fund (Grant No. RSA5980027 and IRN62W0005), the National Research Council of Thailand, and the CIF, Faculty of Science, Mahidol University. PP is thankful for an M.Sc. student scholarship from the Center of Excellence for Innovation in Chemistry (PERCH-CIC).

Conflicts of Interest: The authors declare no conflict of interest.

\section{References}

1. Vosoughifar, A. Photodegradation of dye in waste water using $\mathrm{CaWO}_{4} / \mathrm{NiO}$ nanocomposites co-precipitation preparation and characterization. J. Mater. Sci. Mater. Electron. 2018, 29, 3194-3200. [CrossRef]

2. Chanathaworn, J.; Bunyakan, C.; Wiyaratn, W.; Chungsiriporn, J. Photocatalytic decolurization of basic dye by $\mathrm{TiO}_{2}$ nanoparticle in photoreactor. Songklanakarin J. Sci. Technol. 2012, 34, 203-210.

3. El-Shishtawy, R.M.; Al-Zahrani, F.A.M.; Afzal, S.M.; Razvi, M.A.N.; Al-Amshany, Z.M.; Bakry, A.H.; Asiri, A.M. Synthesis, linear and nonlinear optical properties of a new dimethine cyanine dye derived from phenothiazine. RSC Adv. 2016, 6, 91546-91556. [CrossRef]

4. Gupta, V.K.; Mittal, A.; Gajbe, V.; Mittal, J. Adsorption of basic fuchsin using waste materials bottom ash and deoiled soya-as adsorbents. J. Colloid Interface Sci. 2008, 319, 30-39. [CrossRef]

5. Hou, C.; Hu, B.; Zhu, J. Photocatalytic degradation of methylene blue over $\mathrm{TiO}_{2}$ pretreated with varying concentrations of $\mathrm{NaOH}$. Catalysts 2018, 8, 575. [CrossRef]

6. Sareen, D.; Garg, R.; Grover, N. A Study on removal of methylene blue dye from waste water by adsorption technique using fly ash briquette. IJERT 2014, 3, 610-613.

7. Kumar, R.; El-Shishtawy, R.M.; Barakat, M.A. Synthesis and characterization of $\mathrm{Ag}-\mathrm{Ag}_{2} \mathrm{O} / \mathrm{TiO}_{2} @$ polypyrrole heterojunction for enhanced photocatalytic degradation of methylene blue. Catalysts 2016, 6, 76. [CrossRef]

8. Rouhi, M.; Babamoradi, M.; Hajizadeh, Z.; Maleki, A.; Maleki, S.T. Design and performance of polypyrrole/halloysite nanotubes/ $\mathrm{Fe}_{3} \mathrm{O}_{4} / \mathrm{Ag} / \mathrm{Co}$ nanocomposite for photocatalytic degradation of methylene blue under visible light irradiation. Optik 2020, 212, 164721. [CrossRef]

9. Pan, X.; Chena, X.; Yi, Z. Photocatalytic oxidation of methane over $\mathrm{SrCO}_{3}$ decorated $\mathrm{SrTiO}_{3}$ nanocatalysts via a synergistic effect. Phys. Chem. Chem. Phys. 2016, 18, 31400-31409. [CrossRef]

10. Gharaei, S.K.; Abbasnejad, M.; Maezono, R. Bandgap reduction of photocatalytic $\mathrm{TiO}_{2}$ nanotube by Cu doping. Sci. Rep. 2018, 8, 14192. [CrossRef]

11. Theerthagiri, J.; Salla, S.; Senthil, R.A.; Nithyadharseni, P.; Madankumar, A.; Arunachalam, P.; Maiyalagan, T.; Kim, H.S. A review on $\mathrm{ZnO}$ nanostructured materials: Energy, environmental and biological applications. Nanotechnology 2019, 30, 392001. [PubMed]

12. Thermal Energy Radiation Spectrum. Available online: http://agron-www.agron.iastate.edu/courses/ Agron541/classes/541/lesson09a/9a.3.html (assessed on 1 September 2020). 
13. Karaahmet, O.; Cicek, B. Waste recycling of cathode ray tube glass through industrial production of transparent ceramic frits. J. Air Waste Manag. 2019, 69, 1258-1266. [CrossRef] [PubMed]

14. Alimohammadi, E.; Sheibani, S.; Ataie, A. Preparation of nano-structured strontium carbonate from Dasht-e kavir celestite ore via mechanochemical method. J. Ultrafine Grained Nanostruct. Mater. 2018, 151, 147-152.

15. Owusu, G.; Litz, J.E. Water leaching of $\mathrm{SrS}$ and precipitation of $\mathrm{SrCO}_{3}$ using carbon dioxide as precipitating agent. Hydrometallurgy 2000, 57, 23-29. [CrossRef]

16. Lu, P.; Hu, X.; Li, Y.; Zhang, M.; Liu, X.; He, Y.; Dong, F.; Fu, D.; Zhang, Z. One-step preparation of a novel $\mathrm{SrCO}_{3} / \mathrm{g}-\mathrm{C}_{3} \mathrm{~N}_{4}$ nanocomposite and its application in selective adsorption of crystal violet. RSC Adv. 2018, 8, 6315-6325. [CrossRef]

17. Divya, A.; Mathavan, T.; Harish, S.; Archana, J.; Milton Franklin Benial, A.; Hayakawa, Y.; Navaneetha, M. Synthesis and characterization of branchlet-like $\mathrm{SrCO}_{3}$ nanorods using triethylamine as a capping agent by wet chemical method. Appl. Surf. Sci. 2019, 487, 1271-1278. [CrossRef]

18. Suchanek, W.L.; Riman, R.E. Hydrothermal synthesis of advanced ceramic powders. ASTRJ 2006, 45, $184-193$.

19. Khan, S.A.; Shahid, S.; Kanwai, S.; Rizwan, K.; Mahmood, T.; Ayub, K. Synthesis of novel metal complexes of 2-((phenyl(2-(4-sulfophenyl)hydrazono)methyl)diazinyl)benzoic acid formazan dyes: Characterization, antimicrobial and optical properties studies on leather. J. Mol. Struct. 2018, 1175, 73-89. [CrossRef]

20. Baybars Ali Fil, C.Ö.; Korkmaz, M. Cationic dye (methylene blue) removal from aqueous solution by montmorillonite. Bull. Korean Chem. Soc. 2012, 33, 3184-3190.

21. Song, L.; Zhang, S.; Chen, B. A novel visible-light-sensitive strontium carbonate photocatalyst with high photocatalytic activity. Catal. Commun. 2009, 10, 1565-1568. [CrossRef]

22. Moldovan, A.; Neag, E.; Băbălău-Fussa, V.; Cadar, O.; Micle, V.; Roman, C. Optimized removal of methylene blue from aqueous solution using a commercial natural activated plant-based carbon and Taguchi experimental design. Anal. Lett. 2018, 52, 1-13. [CrossRef]

23. Suqin, L.; Li, W.; Gaopeng, D.; Qiufei, H. Fabrication of $\mathrm{Ag}_{2} \mathrm{CO}_{3} / \mathrm{SrCO}_{3}$ rods with highly efficient visible-light photocatalytic activity. Rare Metal Mat. Eng. 2017, 46, 0312-0316. [CrossRef]

24. Jin, J.; Chen, S.; Wang, J.; Chen, C.; Peng, T. $\mathrm{SrCO}_{3}$-modified brookite/anatase $\mathrm{TiO}_{2}$ heterophase junctions with enhanced activity and selectivity of $\mathrm{CO}_{2}$ photoreduction to $\mathrm{CH}_{4}$. Appl. Surf. Sci. 2019, 476, 937-947. [CrossRef]

25. Jin, S.; Dong, G.; Luo, J.; Ma, F.; Wang, C. Improved photocatalytic NO removal activity of SrTiO 3 by using $\mathrm{SrCO}_{3}$ as a new co-catalyst. Appl. Catal. B-Environ. 2018, 227, 24-34. [CrossRef]

26. Castillejos, A.H.E.; De la Cruz Del, F.P.B.; Uribe, A.S. The direct conversion of celestite to strontium carbonate in sodium carbonate aqueous media. Hydrometallurgy 1996, 40, 207-222. [CrossRef]

27. Zoraga, M.; Kahruman, C. Kinetics of conversion of celestite to strontium carbonate in solutions containing carbonate, bicarbonate and ammonium ions and dissolved ammonia. J. Serb. Chem. Soc. 2014, 79, 345-359. [CrossRef]

28. Zou, X.; Wang, Y.; Liang, S.; Duan, D. Facile synthesis of ultrafine and high purity spherical strontium carbonate via gas-liquid reaction. Mater. Res. Express 2020, 7, 025009. [CrossRef]

29. Yang, L.; Chu, D.; Wang, L.; Ge, G.; Sun, H. Facile synthesis of porous flower-like $\mathrm{SrCO}_{3}$ nanostructures by integrating bottom-up and top-down routes. Mater. Lett. 2016, 167, 4-8. [CrossRef]

30. Wang, Z.; He, G.; Yin, H.; Bai, W.; Ding, D. Evolution of controllable urchin-like $\mathrm{SrCO}_{3}$ with enhanced electrochemical performance via an alternative processing. Appl. Surf. Sci. 2017, 411, 197-204. [CrossRef]

31. Chen, L.; Jiang, J.; Bao, Z.; Pan, J.; Xu, W.; Zhou, L.; Wu, Z.; Chen, X. Synthesis of barium and strontium carbonate crystals with unusual morphologies using and organic additive. Russ. J. Phys. Chem. 2013, 87, 2239-2245.

32. Ni, S.; Yang, X.; Li, T. Hydrothermal synthesis and photoluminescence properties of $\mathrm{SrCO}_{3}$. Mater. Lett. 2011, 65, 766-768.

33. Cao, M.; Wu, X.; He, X.; Hu, C. Microemulsion-mediated solvothermal synthesis of $\mathrm{SrCO}_{3}$ nanostructures. Langmuir 2015, 21, 6093-6096. [CrossRef]

34. Zhang, J.; Xu, J.; Zhang, H.; Yin, X.; Yang, D.; Qian, J.; Liu, L.; Liu, X. Chemical synthesis of $\mathrm{SrCO}_{3}$ microcrystals via a homogeneous precipitation method. Micro Nano Lett. 2011, 6, 119-121.

35. Li, L.; Lin, R.; Tong, Z.; Feng, Q. Crystallization control of $\mathrm{SrCO}_{3}$ nanostructure in imidazolium-based temperature ionic liquids. Mater. Res. Bull. 2012, 47, 3100-3106. [CrossRef] 
36. Wang, G.; Wang, L. Different morphologies of strontium carbonate in water/ethylene glycol and their photocatalytic activity. Fuller. Nanotub. Carbon Nanostructures 2019, 27, 46-51.

37. Alavi, M.A.; Morsali, A. Syntheses and characterization of $\mathrm{Sr}(\mathrm{OH})_{2}$ and $\mathrm{SrCO}_{3}$ nanostructures by ultrasonic method. Ultrason. Sonochem. 2010, 17, 132-138.

38. Song, L.; Li, Y.; He, P.; Zhang, S.; Wu, X.; Fang, S.; Shan, J.; Sun, D. Synthesis and sonocatalytic property of rod-shape $\mathrm{Sr}(\mathrm{OH})_{2} 8 \mathrm{H}_{2} \mathrm{O}$. Ultrason. Sonochemistry 2014, 21, 1318-1324.

39. Li, S.; Zhang, H.; Xu, J.; Yang, D. Hydrothermal synthesis of $\mathrm{f}$ lower-like $\mathrm{SrCO}_{3}$ nanostructures. Mater. Lett. 2005, 59, 420-422. [CrossRef]

40. Neville, G.A.; Becksteadlf, H.D.; Cooney, J.D. Thermal analyses (TGA and DSC) of some spironolactone solvates. Fresenius J. Anal. Chem. 1994, 349, 746-750.

41. Stranic, I.; Pang, G.A.; Hanson, R.K.; Golden, D.M.; Bowman, C.T. Shock tube measurements of the tert-Butanol $+\mathrm{OH}$ reaction rate and the tert $-\mathrm{C}_{4} \mathrm{H}_{8} \mathrm{OH}$ radical $\beta$ - scission branching ratio using isotopic labelling. J. Phys. Chem. A 2013, 117, 4777-4784.

42. Mehrvar, M.; Anderson, W.A.; Young, M.M. Photocatalytic degradation of aqueous organic solvents in the presence of hydroxyl radical scavengers. Int. J. Photoenergy 2001, 3, 187-191. [CrossRef]

43. Patterson, D.A.; Metcalfe, I.S.; Livingston, F.; Livingston, A.G. Wet air oxidation of linear alkylbenzene sulfonate 2 effect of pH. Ind. Eng. Chem. Res. 2001, 40, 5517-5525. [CrossRef]

44. Houas, A.; Lachheb, H.; Ksibi, M.; Elaloui, E.; Guillard, C.; Herrmann, J.M. Photocatalytic degradation pathway of methylene blue in water. Appl. Catal. B Environ. 2001, 31, 145-157. [CrossRef]

45. Rauf, M.A.; Meetani, M.A.; Khaleel, A.; Ahmed, A. Photocatalytic degradation of Methylene Blue using a mixed catalyst and product analysis by LC/MS. Chem. Eng. J. 2010, 157, 373-378. [CrossRef]

46. Technical Application Guide for PHILIPS LED Lamps. Available online: http://yunyangsh.com/pdf_files/ PHILIPS/LED/LED_dengpao/MASTER\%20MR16\%20LED\%2010-50W.pdf (assessed on 31 August 2010).

(C) 2020 by the authors. Licensee MDPI, Basel, Switzerland. This article is an open access article distributed under the terms and conditions of the Creative Commons Attribution (CC BY) license (http://creativecommons.org/licenses/by/4.0/). 